\title{
A bare ground evaporation revision in the ECMWF land-surface scheme: evaluation of its impact using ground soil moisture and satellite microwave data
}

\author{
C. Albergel, G. Balsamo, P. de Rosnay, J. Muñoz-Sabater, and S. Boussetta \\ European Centre for Medium-Range Weather Forecasts (ECMWF), Reading, UK \\ Correspondence to: C. Albergel (clement.albergel@ecmwf.int) \\ Received: 14 May 2012 - Published in Hydrol. Earth Syst. Sci. Discuss.: 30 May 2012 \\ Revised: 15 August 2012 - Accepted: 18 September 2012 - Published: 16 October 2012
}

\begin{abstract}
In situ soil moisture data from 122 stations across the United States are used to evaluate the impact of a new bare ground evaporation formulation at ECMWF. In November 2010, the bare ground evaporation used in ECMWF's operational Integrated Forecasting System (IFS) was enhanced by adopting a lower stress threshold than for the vegetation, allowing a higher evaporation. It results in more realistic soil moisture values when compared to in situ data, particularly over dry areas. Use was made of the operational IFS and offline experiments for the evaluation. The latter are based on a fixed version of the IFS and make it possible to assess the impact of a single modification, while the operational analysis is based on a continuous effort to improve the analysis and modelling systems, resulting in frequent updates (a few times a year). Considering the field sites with a fraction of bare ground greater than 0.2, the root mean square difference (RMSD) of soil moisture is shown to decrease from $0.118 \mathrm{~m}^{3} \mathrm{~m}^{-3}$ to $0.087 \mathrm{~m}^{3} \mathrm{~m}^{-3}$ when using the new formulation in offline experiments, and from $0.110 \mathrm{~m}^{3} \mathrm{~m}^{-3}$ to $0.088 \mathrm{~m}^{3} \mathrm{~m}^{-3}$ in operations. It also improves correlations. Additionally, the impact of the new formulation on the terrestrial microwave emission at a global scale is investigated. Realistic and dynamically consistent fields of brightness temperature as a function of the land surface conditions are required for the assimilation of the SMOS data. Brightness temperature simulated from surface fields from two offline experiments with the Community Microwave Emission Modelling (CMEM) platform present monthly mean differences up to $7 \mathrm{~K}$. Offline experiments with the new formulation present drier soil moisture, hence simulated brightness temperature with its surface fields are larger. They are also closer to SMOS remotely sensed brightness temperature.
\end{abstract}

\section{Introduction}

Soil moisture plays a fundamental role in the partitioning of mass and energy fluxes between the hydrosphere, biosphere and atmosphere because it controls both evaporation and transpiration fluxes from bare soil and vegetated areas, respectively. In addition, it is a key variable in hydrological processes (i.e. runoff, evaporation from bare soil and transpiration from the vegetation cover) and has an impact on plant growth and carbon fluxes (Dirmeyer et al., 1999; Entekhabi et al., 1999). Its initialisation is of crucial importance for Numerical Weather Prediction (NWP) models and this topic has been extensively explored in the literature (e.g. Shukla and Mintz, 1982; Dirmeyer, 2002; Douville et al., 2001); soil moisture might play a role in meteorological forecasting (Seneviratne et al., 2010).

The second phase of the multi-institutional numerical modelling experiment GLACE-2 (Global Land-Atmosphere Coupling Experiment) led to several insights about how the realistic initialisation of soil moisture can have a significant impact on the skill of precipitation and air temperature forecast skill at the subseasonal scale (Koster et al., 2011). Notably, while both wet and dry land-surface-model initialisations are likely to generate skill in different areas of the world, dry initialisation provides more skill at the transition between soil-moisture and energy-availabilitycontrolled evaporation. The first phase of GLACE (Koster et al., 2004) focused on the atmospheric response to soil moisture variations. Meteorological variables such as precipitation and air temperature were found to be particularly affected by soil moisture variations in specific areas: the transition zones between arid and humid areas. Dry land has recently received more attention both in literature (Wang et al., 
2012) and in several initiatives on the Drought Early Warning (DEW) information services worldwide (WMO, Drought monitoring and early warning, 2006). Many studies have focused on the coupled bare soil-canopy processes and the ability of land surface models to simulate bare soil processes has also been of interest (Desborough et al., 1996). Albergel et al. (2012a, b) demonstrated the good quality of the European Centre for Medium-Range Weather Forecasts (ECMWF) soil moisture products with respect to globalground based in situ observations. They found good level of correlations despite the high values of root mean square difference (RMSD), which indicate that ECMWF products tend to overestimate soil moisture, particularly over dry areas. To overcome this problem, an improved bare ground evaporation scheme over dry land (Balsamo et al., 2011) was implemented in ECMWF's Integrated Forecasting System (IFS) in November 2010. It is expected that the new scheme will reduce the soil moisture over bare soil by enhancing evaporation, resulting in more realistic soil moisture when compared to in situ data. Because the improved bare ground evaporation was implemented in 2010, along with other modifications affecting soil moisture (e.g. an Extended Kalman Filter for soil moisture analysis, de Rosnay et al., 2011, 2012), it is difficult to isolate the impact of the new evaporation scheme. For this reason, offline experiments were carried out with and without the new bare ground evaporation to analyse the impact of the specific modification. This study aims at evaluating the impact of this new evaporation scheme on soil moisture.

In the framework of the Soil Moisture and Ocean Salinity (SMOS, Kerr, 2007; Kerr et al., 2010) mission, ECMWF is implementing the direct assimilation of near real time brightness temperature (TB) in the L-band (Sabater et al., 2012). It will only be effective if realistic and dynamically consistent fields of TB are simulated as a function of land-surface conditions. At ECMWF, the Community Microwave Emission Modelling platform (CMEM, Holmes et al., 2008; Drusch et al., 2009a; de Rosnay et al., 2009) is used to simulate TB. Surface soil moisture is, amongst other surface fields, coupled with CMEM to produce ECMWF's first-guess TB. The main objective of this study is to evaluate the new evaporation formulation on soil moisture; however, as the improved bare ground evaporation is expected to affect surface fields such as soil moisture, it also assesses its impact on simulated TB.

After a description of the ECMWF's analysis and soil moisture products used in this study, the new bare ground evaporation formulation is presented followed by a description of the in situ observations required to evaluate soil moisture analyses. Next, the CMEM platform is briefly described along with the remotely-sensed SMOS TB data set. Then the impact of the improved bare ground evaporation is assessed using (i) two offline experiments and (ii) ECMWF's operational IFS and in situ soil moisture data for the period 2010 2011 (only 2010 for the offline experiments). Finally, sur- face soil moisture and soil temperature fields, as well as snow depth and density fields from the two offline experiments, are coupled with the CMEM platform to simulate the TB data set at a global scale; they permit the study of the sensitivity of CMEM to the new bare ground evaporation. Finally, the two TB data sets are compared to SMOS TB observations for the year 2010 .

\section{Material and methods}

In situ soil moisture observations are important for evaluating soil moisture products. In this study use was made of soil moisture data from the NRCS-SCAN network (Natural Resources Conservation Service - Soil Climate Analysis Network) in the United States (Schaefer and Paetzold, 2000). They were obtained through the International Soil Moisture Network (ISMN, Dorigo et al., 2011, http://www.ipf.tuwien. ac.at/insitu/), a new data hosting centre where globally available ground-based soil moisture measurements are collected, harmonized and made available to users. Data at 148 stations in 2010 and 2011 were used to evaluate soil moisture from offline experiments and the operational IFS. The soil moisture data sets used in this study are presented in Table 1.

\subsection{ECMWF's land surface analysis}

Data produced at ECMWF include a large variety of surface parameters that describe the atmosphere as well as oceanwave and land-surface conditions (more information at: http: //www.ecmwf.int/products/). The core atmospheric assimilation system at ECMWF relies on the four-dimensional variational (4D-Var) data assimilation scheme described in Rabier et al. (2000) and Mahfouf and Rabier (2000). It has an observation time frame of $12 \mathrm{~h}$ (Bouttier, 2001). Data provided by satellite sensors (from microwave and infrared radiometers) as well as conventional observations (e.g. radiosonde network) are ingested within the 4D-Var. Use is also made of surface observations such as surface pressure, humidity and wind.

For several decades, NWP initialisation has relied on data assimilation approaches which use satellite data to analyse atmospheric variables. Land-surface initialisation is generally independent from the atmospheric system and is based on ground measurements of screen-level variables as a proxy for soil moisture. In recent years, major upgrades have been implemented in the land-surface modelling and analysis systems of the IFS with respect to soil moisture: (i) an improved soil hydrology model (Balsamo et al., 2009); (ii) a new snow scheme (Dutra et al., 2010); and (iii) a multiyear satellitebased vegetation climatology (Boussetta et al., 2010) together with enhanced bare ground evaporation (Balsamo et al., 2011). A new soil moisture analysis scheme, based on a point-wise Extended Kalman Filter (EKF) for the global land surface, has also been developed and this was implemented 
Table 1. The soil moisture products used in this study. NWP stands for numerical weather prediction and LSM for land-surface model.

\begin{tabular}{|c|c|c|c|c|c|c|}
\hline $\begin{array}{l}\text { Soil Moisture } \\
\text { data set }\end{array}$ & Type & $\begin{array}{l}\text { Soil layer } \\
\text { depth }(\mathrm{cm})\end{array}$ & $\begin{array}{l}\text { Considered } \\
\text { period }\end{array}$ & Spatial resolution & Number of stations & Land use \\
\hline $\begin{array}{l}\text { ECMWF } \\
\text { operational } \\
\text { analysis }\end{array}$ & $\begin{array}{l}\text { NWP } \\
\text { analysis }\end{array}$ & $0-7$ & $\begin{array}{l}\text { January } 2010 \text { to } \\
\text { December } 2011\end{array}$ & $\begin{array}{l}\text { Before } 26 \text { January 2010: } \\
\sim 25 \mathrm{~km}(\mathrm{~T} 799) \\
\text { from } 27 \text { January } 2010: \\
\sim 16 \mathrm{~km}(\mathrm{~T} 1279)\end{array}$ & Global product & Global product \\
\hline $\begin{array}{l}\text { ECMWF } \\
\text { BEVAP_OLD } \\
\text { [control experiment] }\end{array}$ & $\begin{array}{l}\text { ERA-Interim } \\
\text { driven } \\
\text { LSM run }\end{array}$ & $0-7$ & $\begin{array}{l}\text { January } 2010 \text { to } \\
\text { December } 2010\end{array}$ & $\sim 80 \mathrm{~km}(\mathrm{~T} 255)$ & Global product & Global product \\
\hline $\begin{array}{l}\text { ECMWF } \\
\text { BEVAP_NEW } \\
\text { [test] }\end{array}$ & $\begin{array}{l}\text { ERA-Interim } \\
\text { driven } \\
\text { LSM run }\end{array}$ & $0-7$ & $\begin{array}{l}\text { January } 2010 \text { to } \\
\text { December } 2010\end{array}$ & $\sim 80 \mathrm{~km}(\mathrm{~T} 255)$ & Global product & Global product \\
\hline $\begin{array}{l}\text { NRCS-SCAN } \\
\text { (US) }\end{array}$ & $\begin{array}{l}\text { In situ } \\
\text { observations }\end{array}$ & 5 & $\begin{array}{l}\text { January } 2010 \text { to } \\
\text { December } 2011\end{array}$ & Local scale & 148 stations & $\begin{array}{l}\text { Natural fallow } \\
\text { or short grass }\end{array}$ \\
\hline
\end{tabular}

in the IFS (Drusch et al., 2009b; de Rosnay et al., 2011, 2012) in November 2010.

The model forecast for the land surface analysis is provided by the TESSEL land surface scheme (Van den Hurk et al., 2000), which was then upgraded to H-TESSEL (Van den Hurk and Viterbo, 2003; Balsamo et al., 2009) with an improved soil hydrology. H-TESSEL development was a response to weaknesses in the TESSEL hydrology-a Hortonian runoff scheme hardly producing surface runoff while the choice of a single global soil texture was not able to characterize different soil moisture regimes. So for H-TESSEL, the formulation of the soil hydrological conductivity and diffusivity was revised to be spatially variable according to a global soil texture map (FAO/UNESCO Digital Soil Map of the World, DSMW, FAO, 2003). H-TESSEL was implemented in the IFS in November 2007. It was verified in various ways, including field site comparison, data assimilation and modelling experiments by Balsamo et al. (2009). Albergel et al. (2012b) also provide a detailed evaluation of $\mathrm{H}$ TESSEL soil moisture. Analyses are available at four depths $(0-7,7-28,28-100$ and $100-289 \mathrm{~cm})$. The soil heat budget follows a Fourier diffusion law, modified to take into account soil water freezing/melting according to Viterbo et al. (1999). The energy equation is solved with a net ground heat flux as the top boundary condition and a zero flux at the bottom. The water balance at the surface (i.e. the change in water storage of the soil moisture, interception reservoir and accumulated snowpack) is computed as the difference between the precipitation and (i) the evaporation of soil, vegetation and interception water and (ii) surface and subsurface runoff. First precipitation is collected in the interception reservoir until it is saturated. Then, excess precipitation is partitioned between surface runoff and infiltration into the soil column. HTESSEL's formulation of the soil hydrological conductivity and diffusivity is spatially variable according to a global soil texture map (FAO/UNESCO Digital Soil Map of the World, DSMW, FAO, 2003). Surface runoff is based on variable in- filtration capacity. At the end of each data assimilation cycle, an adjustment to the model forecast (e.g. soil moisture) is produced; it usually refers to analysis increment and represents the net response of the variational data assimilation to all observations used.

Three analyses schemes for the surface (and near-surface) variables are currently used in operations. They are based on spatial Optimal Interpolation (2D-OI, for snow depth and screen-level analyses); column Optimal Interpolation (1DOI, for soil and snow temperature analysis); and an EKF (for soil moisture analysis, Drusch et al., 2009b; de Rosnay et al., 2011, 2012). Analysis of surface parameters is decoupled from the main atmospheric analysis. Firstly an OI scheme produces estimates of screen-level temperature and relative humidity by combining synoptic observations over land with background estimates (short-range forecasts) from the most recent analysis (Douville et al., 2000). Analysed fields of screen-level temperature and relative humidity are then used to update estimates of soil moisture (and soil temperature) for the layers of the model using the EKF analysis. While producing the forecast, the model estimates a wide variety of physical variables including precipitation. Even if not directly observed, the model estimates are constrained by the observations (in situ measurements of temperature and humidity) used to initialise the forecast; their accuracy relies on the quality of the model physics as well as that of the analysis.

\subsubsection{Soil moisture products}

In this section a description is given of the major differences between the deterministic operational suite and the offline experiments with respect to soil moisture.

The version of IFS used in operations at ECMWF from January 2010 to December 2011 spans from 35r3 to $37 \mathrm{r} 3$ (more information at: http://www.ecmwf.int/research/ ifsdocs/). There are continuous efforts to improve the 
analysis and modelling schemes (i.e. changes in spatial and vertical resolutions, data assimilation, parameterizations and sources of data), resulting in frequent updates of the IFS (a few times a year). Before the implementation of cycle 36r4 in November 2010, the assimilation technique used was the OI (Mahfouf, 1991; Mahfouf et al., 2000b). The EKF was implemented in operations to optimally combine model data with conventional observations and satellite measurements. In its current configuration, the EKF soil moisture analysis uses meteorological observations of screen-level parameters close to the surface, as with the previous OI method. However, due to the flexibility of Kalman-based techniques, the EKF can handle different sources of observations (Mahfouf et al., 2009) and offers a wide range of development possibilities including the use of remotely sensed data such as ASCAT (Advanced Scatterometer, Wagner et al., 2007) and SMOS (Kerr, 2007; Kerr et al., 2010). The operational IFS soil moisture analysis is produced four times each day (i.e. at 00:00, 06:00, 12:00 and 18:00 UTC); it has a spatial resolution of about $25 \mathrm{~km}$ (T799) until 26 January 2010 and then it is about $16 \mathrm{~km}$ (T1279). Analyses at 00:00 UTC are considered in this study.

The offline experiments used in this study are based on IFS cycle 36r4. They are produced daily at 00:00, 06:00, 12:00 and 18:00 UTC at a spatial resolution of about $80 \mathrm{~km}$ (T255). Offline experiments are a response to reproduce the land-surface model state in between two reanalyses (e.g. the two latest reanalyses of ECMWF are ERA-Interim, Dee et al., 2011 and ERA-40, Uppala et al., 2005). Reanalyses such as ERA-Interim are produced by a fixed version of the IFS (for the main component of the atmospheric model and data assimilation) and have the advantage of being consistent over a long period. Offline experiments are based on the same principle and take into account specific improvements implemented in the operational IFS (e.g. the ERAInterim reanalysis land-surface scheme is based on the TESSEL scheme while H-TESSEL is used for offline experiments in this study). Offline experiments can be considered as add-ons before future generations of reanalyses are produced at ECMWF. They are driven by ERA-Interim (Dee et al., 2011) global atmospheric reanalyses. The difference between the two experiments concerns only the bare ground evaporation. For one, the bare ground evaporation over dry land has been enhanced by adopting a lower stress threshold than for the vegetation, allowing for higher evaporation (BEVAP_NEW). Its control experiment without the new bare ground evaporation is called BEVAP_OLD.

\subsubsection{New bare ground evaporation}

This section gives a description of the new bare ground formulation. It is in agreement with the experimental findings of Mahfouf and Noilhan (1991) and results in more realistic soil moisture values for dry land (Balsamo et al., 2011). Indeed, the evaporation from nonvegetated areas responds to a differ- ent physical mechanism compared to densely vegetated areas. Over bare soil, the vaporisation of water in the soil pores takes place in a thin layer close to the surface-atmosphere interface; this is a direct effect of incoming solar radiation providing the latent heat requirements. Atmospheric conditions such as air temperature, humidity, wind velocity and radiation, as well as soil conditions (e.g. water content and roughness length) play a role in modulating the evaporation processes (Hillel, 1980). The relationship between soil moisture and bare soil evaporation is generally parameterized in landsurface models. Mahfouf and Noilhan (1991) compared several of these formulations; in these studies, bare soil evaporation formulations were halted when the soil was completely dry (for soil moisture close to zero). In the previous TESSEL scheme, linking of soil moisture and evaporation was assumed to be linear between the permanent wilting point and the field capacity values for soil moisture. With the introduction of a tiling approach, the same stress function was applied to both vegetated and nonvegetated tiles, neglecting the fact that wilting point is a soil moisture threshold that applies uniquely to vegetated areas. The formulation of the bare soil evaporation has been revisited in the latest H-TESSEL version to allow a smooth transition between vegetated and nonvegetated areas and to realign the formulation of bare ground evaporation with studies in the literature. Evapotranspiration process $(E)$ is parameterized for each tile $i$ accounting for canopy and soil resistance as:

$E_{i}=\frac{\rho_{\mathrm{a}}}{r_{\mathrm{a}}+r_{\mathrm{c}}}\left[q_{\mathrm{L}}-q_{\mathrm{sat}}\left(T_{\mathrm{sk}, i}\right)\right]$

where $\rho_{\mathrm{a}}$ is the air density; $q_{\mathrm{L}}$ is the humidity at the lowest model level; $q_{\mathrm{sat}}\left(T_{\mathrm{sk}, i}\right)$ is the saturated humidity for the vegetation skin temperature $T_{\mathrm{sk}, i} ; r_{\mathrm{a}}$ is the aerodynamic resistance; and $r_{\mathrm{c}}$ is the canopy resistance. Equation (1) is valid for vegetated and nonvegetated tile $i$ in the absence of snow and interception water.

For vegetated tiles, the canopy resistance is formulated according to Jarvis (1976):

$r_{\mathrm{c}}=\frac{r_{\mathrm{s}, \min }}{\mathrm{LAI}} f_{1} f_{2} f_{3}$

with LAI prescribed from a MODIS satellite-based data set as detailed in Boussetta et al. (2011). In the canopy resistance formulation, the $r_{\mathrm{s}, \min }$ is the minimum stomatal resistance and $f_{1}$ and $f_{3}$ are inhibition functions expressing the shortwave radiation deficit and atmospheric humidity deficit, respectively. The soil moisture inhibition function, $f_{2}$, depends on the root-zone soil wetness $\left(w_{\text {root }}\right)$ normalized between the wilting point $\left(w_{\text {wilt }}\right)$ and the field capacity $\left(w_{\mathrm{fc}}\right)$ therefore:

$f_{2}=\frac{w_{\text {root }}-w_{\text {wilt }}}{w_{\text {fc }}-w_{\text {wilt }}}$.

For nonvegetated tiles, $r_{\mathrm{c}}$ is uniquely dependent on the soil moisture of the first soil layer, so $f_{2}$ is modified to be computed as a function of surface soil moisture $f_{2}\left(w_{\text {layer1 } 1}\right)$ and a 
minimum soil resistance $r_{\text {soil, min }}$ :

$r_{\mathrm{c}}=r_{\mathrm{soil}, \min } \cdot f_{2}\left(w_{\text {layer1 } 1}\right)$.

In the new formulation, the $f_{2}^{\prime}$ for bare ground is calculated as:

$f_{2}^{\prime}=\frac{w_{\mathrm{root}}-w_{\min }}{w_{\mathrm{fc}}-w_{\min }}$

where $w_{\min }$ is a weighted average of the wilting point and residual soil moisture content $\left(w_{\text {res }}\right)$. The weights are given by the vegetation cover fraction "veg" (van den Hurk et al., 2000), so that:

$w_{\min }=\operatorname{veg} \cdot w_{\text {wilt }}+(1-\operatorname{veg}) \cdot w_{\text {res }}$

In BEVAP_OLD experiment, Eq. (3) is used while it is Eq. (5) in BEVAP_NEW.

\subsection{In situ soil moisture observations: the NRCS-SCAN network}

The SCAN network (http://www.wcc.nrcs.usda.gov/scan/) is a comprehensive, nationwide soil moisture and climate information system designed to provide data to support natural resource assessments and conservation activities. It is administered by the United States Department of Agriculture (USDA) Natural Resources Conservation Service (NRCS) through the National Water and Climate Centre (NWCC), in cooperation with the NRCS National Soil Survey Center. The system focuses on agricultural areas of the USA. The observing network monitors soil temperature and soil moisture at several depths, soil water level, air temperature, relative humidity, solar radiation, wind, precipitation and barometric pressure, amongst others. SCAN data are used for a variety of purposes, ranging from global climate modelling to agricultural studies. Data are collected by a dielectric constant measuring device; typical measurements at 2 inches (about $5 \mathrm{~cm}$ ) are used. The vegetation cover at those sites consists generally of natural fallow or short grass. In this study, all the stations of the NRCS-SCAN network providing data in 2010 and 2011 are retained (leading to a total of 148 stations). The location of the stations of the NRCS-SCAN network are shown on Fig. 1.

\subsection{Statistical comparison between analysis and in situ observations}

A usual step for evaluating soil moisture products from model is to determine whether their behaviour matches the observations. Hence in situ measurements of soil moisture are a highly valuable source of information. For all stations, correlations ( $R$, Eq. 7), bias (in situ minus analysis), root mean square difference (RMSD, Eq. 8) and $p$-value (a measure of the correlation significance) are calculated. The latter indicates the significance of the test; the $95 \%$ confidence

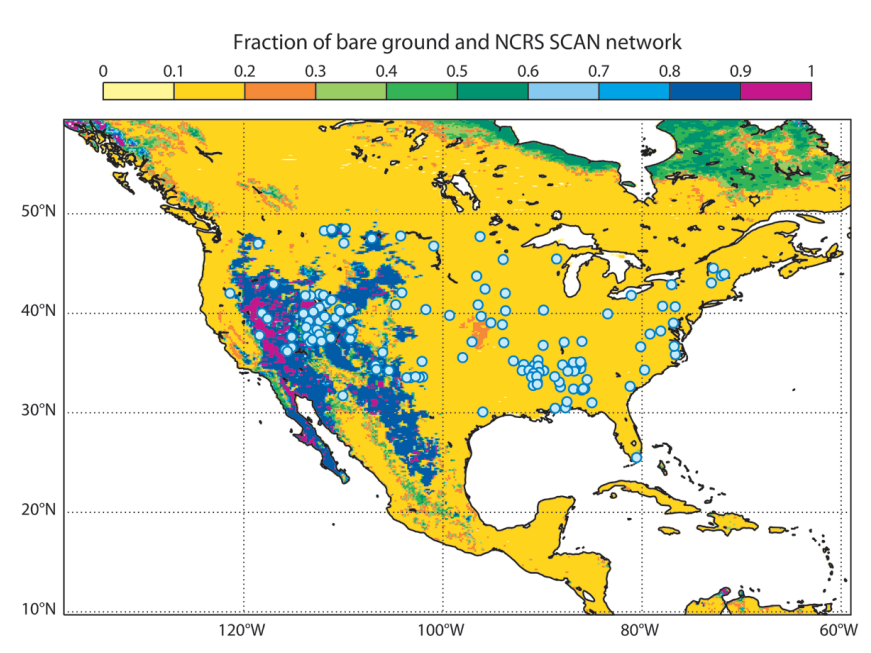

Fig. 1. Location of the different in situ soil moisture stations used in this study (blue circles); the stations belong to the NRCS-SCAN network (United States). Colour scale represents the fraction of bare ground.

interval is used in this study (as in Rüdiger et al., 2009; Albergel et al., 2009, 2010); only configurations where the $p$ value is below 0.05 (i.e. the correlation is not a coincidence) are retained.

$$
\begin{gathered}
R=\sqrt{1-\frac{\sum\left(\mathrm{SSM}_{\text {products }}-\mathrm{SSM}_{\text {insitu }}\right)^{2}}{\sum\left(\mathrm{SSM}_{\text {products }}-\overline{\left.\mathrm{SSM}_{\text {insitu }}\right)^{2}}\right.}} \\
\mathrm{RMSD}=\sqrt{\overline{\sum\left(\mathrm{SSM}_{\text {products }}-\mathrm{SSM}_{\mathrm{insitu}}\right)^{2}}}
\end{gathered}
$$

As in situ data may contain errors (instrumental and representativeness), they are not considered as "true" soil moisture. This is emphasised by using the RMS difference terminology instead of RMS error. In situ observations of soil moisture at the NRCS-SCAN stations are associated with soil temperature measurements. The observations of soil moisture were flagged for temperature below 4 degrees Celsius to avoid frozen conditions. When considering TB, the standard deviation (STD) is also computed.

To avoid seasonal effects, monthly anomaly time-series are calculated. The difference from the mean is produced for a sliding window of five weeks (if there are at least five measurements in this period), and the difference is scaled to the standard deviation. For each surface soil moisture estimate at day $(i)$, a period $F$ is defined, with $F=[i-17, i+17]$ (corresponding to a five-week window). If at least five measurements are available in this period, the average soil moisture value and the standard deviation are calculated. The Anomaly (Ano) is then given by

$\operatorname{Ano}(i)=\frac{\operatorname{SSM}(i)-\overline{\operatorname{SSM}(F)}}{\operatorname{stdev}(\operatorname{SSM}(F))}$. 
The same equation is used to compute in situ anomaly timeseries which can be compared with that from ECMWF's analyses.

\subsection{The terrestrial microwave emission modelling}

\subsubsection{The Community Microwave Emission Modelling (CMEM) platform}

The CMEM platform has been developed by ECMWF as the forward operator for low frequency passive microwave TB (from $1 \mathrm{GHz}$ to $20 \mathrm{GHz}$ ) of the surface in the framework of the SMOS mission. CMEM is one of the ESA (European Space Agency) SMOS tools and it is available to the entire community through the ECMWF web page: http://www.ecmwf.int/research/ESA_projects/SMOS/ cmem/cmem_doc.html.

CMEM represents the top of atmosphere TB as a result of the contributions from the following dielectric layers: soil, vegetation and atmosphere. The physics of CMEM is based on the parameterizations used in the L-Band Microwave Emission of the Biosphere (L-MEB, Wigneron et al., 2007) and the Land Surface Microwave Emission Model (LSMEM, Drusch et al., 2001); it includes a modular choice of the physical parameterizations for the various dielectric layers. Multiple parameterizations for the dielectric constant, the effective temperature, the smooth emissivity, soil roughness, vegetation optical depth and the atmospheric opacity lead to 1440 combinations when using CMEM (de Rosnay et al., 2009). The best CMEM configuration according to the finding of de Rosnay et al. (2009) is retained for this study. Sabater et al. (2011) also used this configuration, replacing, however, the soil roughness parameterization of Choudhury (1979) by the one proposed by Wigneron et al. (2001), because the former showed little sensitivity over larger regions.

\subsubsection{SMOS brightness temperature}

SMOS consists of a microwave imaging radiometer with an aperture synthesis, collecting top of atmosphere full polarized radiances from the scene, viewed by its antennas through their power patterns. It is a Y-shaped instrument with several elementary antennas regularly spaced along the arms (69 in total) which provide, at each integration step, a full image (circa $1000 \times 1200 \mathrm{~km}$ ) at either two polarisations or full polarisation, of the Earth's surface (Kerr et al., 2007, 2010). The spatial resolution is about $40 \mathrm{~km}$ and the globe is fully imaged at least twice every three days (ascending and descending orbits). Any points at the surface are viewed frequently at different angles and polarisations. The angular information is used to separate the different contributions (soil-vegetation) to the signal (Wigneron et al., 2000). The signal measured at satellite level is a TB for the L-band consisting of four main contributions: (i) the up-welling atmospheric emission; (ii) the Earth's surface emission, attenu- ated by the atmosphere; (iii) the atmospheric down-welling atmospheric emission reflected at the surface and attenuated along the upward path by the atmosphere; and (iv) the cosmic background emission attenuated by the atmosphere, reflected at the surface and attenuated again along the upward path by the atmosphere. SMOS Near Real Time (NRT) products are processed at the European Space Astronomy Centre (ESAC) and sent to ECMWF via the SMOS Data Processing Ground Segment (DPGS) interface. ECMWF is involved in global monitoring and data assimilation of the SMOS mission data. The development of a data monitoring system for the SMOS near real time product provides a timely quality check for the European Space Agency (ESA) and the SMOS calibration and validation teams. More information and comparison between SMOS data and modelled TB are available through ECMWF web pages: http: //www.ecmwf.int/research/ESA_projects/SMOS/index.html.

\section{Results}

\subsection{Impact of the new bare ground evaporation on soil moisture}

\subsubsection{Using Offline experiments}

Figure 2 illustrates the mean soil moisture for both BEVAP_OLD and BEVAP_NEW for August 2010. A simple look at Figs. 1 and 2 permits to identify that areas with a high fraction of bare soil are drier with BEVAP_NEW than with BEVAP_OLD. The statistical scores for the comparison between either BEVAP_OLD or BEVAP_NEW and the stations from the NRCS-SCAN network are presented in Table 2. As indicated in NRCS-SCAN website, data are provisional and subject to revision and very little control is applied to measurements from NRCS-SCAN. Dharssi et al. (2011) used a simple process to identify stations where sensors might be dysfunctional. Stations are rejected based on the scores obtained when compared to their experiments (in term of correlations, RMSDs and biases). As this study aims to assess the impact of the new bare ground experiment, mostly in terms of RMSD, a similar is applied based only on the correlation level. Stations for which either BEVAP_OLD or BEVAP NEW have a correlation less than 0.3 are rejected (as in Dharssi et al., 2011). This rather strict process has probably removed some good stations too (e.g. in areas where the model might not realistically represent soil moisture). Also, stations with a nonsignificant correlation are rejected ( $p$-value $<0.05$ ). This filtering of the NRCS-SCAN stations, results in 122 stations being available (out of 148) for the comparison of the two offline experiments. Table 3 presents the bias between stations of the NRCS-SCAN network and BEVAP_OLD. When biases are computed for stations with a fraction of bare soil greater that 0.6 , bias in on average $-0.100 \mathrm{~m}^{3} \mathrm{~m}^{-3}$, it is $-0.079 \mathrm{~m}^{3} \mathrm{~m}^{-3}$ when computed for 


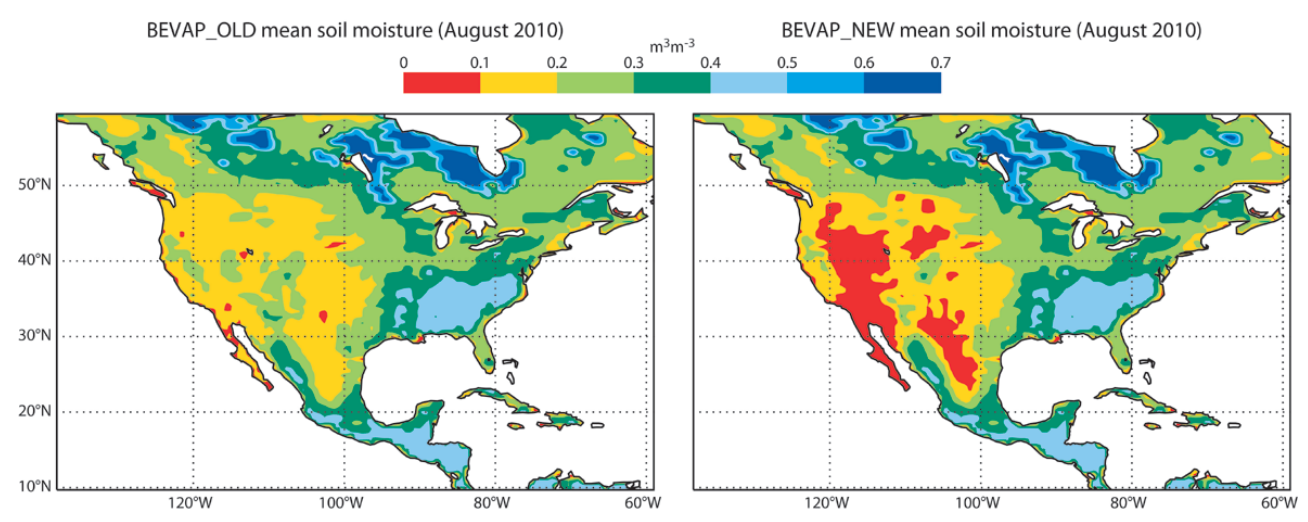

Fig. 2. Mean soil moisture for BEVAP_OLD (left) and BEVAP_NEW (right) (August 2010).

Table 2. Statistical scores for the comparison between ECMWF surface soil moisture (offline experiments, BEVAP_OLD and BEVAP_NEW) and in situ data for all the stations from the NRCS-SCAN (USA) network over the 2010 period.

\begin{tabular}{lrrrrr}
\hline $\begin{array}{l}\text { Soil Moisture } \\
\text { data set }\end{array}$ & N stations & $R$ & $\begin{array}{r}\text { Anomaly } \\
R\end{array}$ & $\begin{array}{r}\text { Bias } \\
\left(\mathrm{m}^{3} \mathrm{~m}^{-3}\right)\end{array}$ & $\begin{array}{r}\text { RMSD } \\
\left(\mathrm{m}^{3} \mathrm{~m}^{-3}\right)\end{array}$ \\
\hline $\begin{array}{l}\text { ECMWF BEVAP_OLD } \\
\text { [control experiment] }\end{array}$ & 122 & 0.60 & 0.54 & -0.095 & 0.135 \\
$\begin{array}{l}\text { ECMWF BEVAP_NEW } \\
\text { [test] }\end{array}$ & 122 & 0.62 & 0.55 & -0.064 & 0.124 \\
\hline
\end{tabular}

stations with a fraction of bare soil greater that 0.1 . These results indicate that ECMWF soil moisture product negative (wet) biases are more pronounced in areas with a high fraction of bare soil, and comfort the modification of the wilting point in Eq. (3) to a weighted average of the wilting point in Eq. (5), taking into account the vegetation cover fraction (Eq. 6). For all stations, the average correlations for volumetric time-series are 0.60 for BEVAP_OLD (control) and 0.62 for BEVAP_NEW (test). Biases (in situ minus analyses) are on average $-0.095 \mathrm{~m}^{3} \mathrm{~m}^{-3}$ and $-0.064 \mathrm{~m}^{3} \mathrm{~m}^{-3}$, RMSDs are $0.135 \mathrm{~m}^{3} \mathrm{~m}^{-3}$ and $0.124 \mathrm{~m}^{3} \mathrm{~m}^{-3}$ for BEVAP_OLD and BEVAP_NEW, respectively. Despite a small decrease in RMSD for BEVAP_NEW, both values are high. The new formulation (Eq. 5) is expected to enhance evaporation over bare ground, hence for each station, the fraction of bare ground (according to the model) was used as a filter to evaluate the impact of the new formulation on RMSD. The RMSD difference between BEVAP_OLD, BEVAP_NEW and stations of the NRCS-SCAN network as a function of the fraction of bare ground is displayed on Fig. 3. It identifies a threshold value (0.2) below, for which the fraction of bare soil is too small for the new formulation to have an impact on RMSD. When scores are computed for stations with a fraction of bare ground greater than or equal to 0.2 (35 stations with significant $R$ values), the correlations, biases and RMSDs are 0.63, $-0.086 \mathrm{~m}^{3} \mathrm{~m}^{-3}, 0.118 \mathrm{~m}^{3} \mathrm{~m}^{-3}$ for BEVAP_OLD and 0.65 , $0.0007 \mathrm{~m}^{3} \mathrm{~m}^{-3}, 0.087 \mathrm{~m}^{3} \mathrm{~m}^{-3}$ for BEVAP_NEW. This decrease in the RMSD for BEVAP_NEW (from $0.118 \mathrm{~m}^{3} \mathrm{~m}^{-3}$ to $0.087 \mathrm{~m}^{3} \mathrm{~m}^{-3}$ ), leading to a more realistic soil moisture product regarding the in situ data, is attributed only to the new bare ground evaporation formulation. Figure 4 illustrates the two offline runs as well as the in situ observations for one site located in Utah. Minimum values of BEVAP_OLD soil moisture are limited by the dominant wilting point for vegetation types, however, ground data indicate much drier conditions, as is clearly observed from May to September 2010. The new bare ground evaporation allows the model to go below this wilting point so the BEVAP_NEW analysis is in much better agreement with the observations than that for BEVAP_OLD. Along with the decrease in RMSD, one may note an increase in the correlation (from 0.63 to 0.65 ). Also BEVAP_NEW has a more realistic decrease in soil moisture after a precipitation event due to its higher water holding capacity and this explains the slightly better correlations.

Considering the short-term variability, the average correlations for the monthly anomaly time series are 0.54 for BEVAP_OLD and 0.55 for BEVAP_NEW. Correlations of volumetric time series are larger than those for the monthly anomaly time-series. The good level of correlation of the volumetric time series is largely explained by seasonal variations, which are suppressed in monthly anomalies.

\subsubsection{Using the operational product}

The new bare ground evaporation formulation was implemented in operations in November 2010. Its impact on the operational analysis was assessed for the 2010-2011 


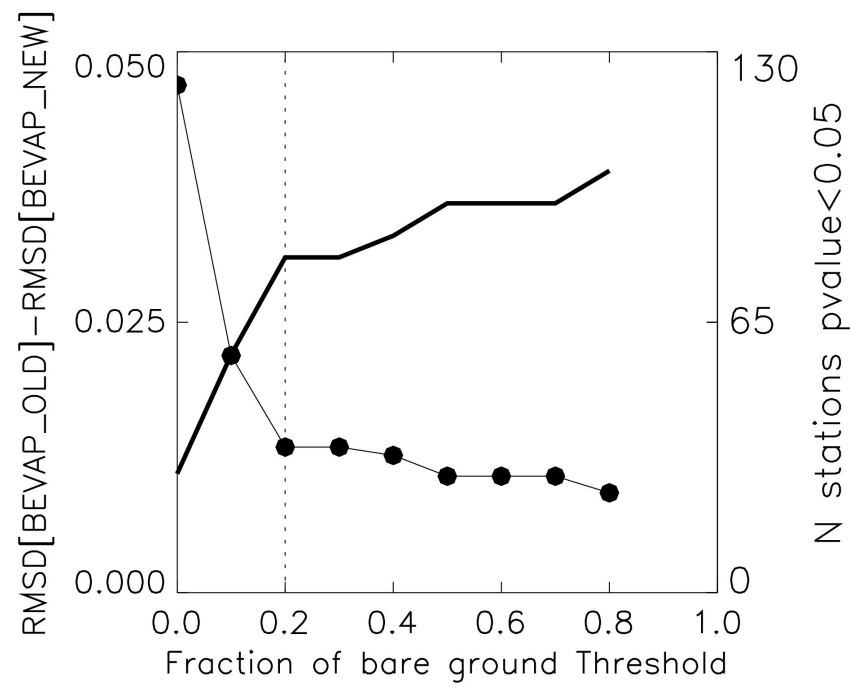

Fig. 3. Soil moisture RMSD between BEVAP_OLD and BEVAP_NEW as a function of the fraction of bare ground (black solid curve, left y-axis), the number of in situ stations used (for which significant correlation is obtained between observations and model time-series) is also presented (black dots, right y-axis). The dashed line represents a bare soil fraction threshold below which the sensitivity of soil moisture to the new evaporation formulation is less pronounced.

period. Results are presented in Table 4 and illustrated by Fig. 5. The same threshold of 0.2 for the fraction of bare ground was used. The correlations, bias and RMSD are $0.59,-0.076 \mathrm{~m}^{3} \mathrm{~m}^{-3}$ and $0.110 \mathrm{~m}^{3} \mathrm{~m}^{-3}$ for 2010 , and 0.69 , $-0.010 \mathrm{~m}^{3} \mathrm{~m}^{-3}, 0.088 \mathrm{~m}^{3} \mathrm{~m}^{-3}$ for 2011 . Figure 5 illustrates the soil moisture time-series for three stations with different fractions of bare ground $(\sim 0.46, \sim 0.79$ and $\sim 0.15$ from top to bottom). Compared to 2010 , the station with a fraction of bare ground of 0.79 has a lower value of RMSD in 2011 than a station with a fraction of 0.15 . As for BEVAP_OLD and BEVAP_NEW, the operational analysis is in much better agreement with the observations for 2011 (with the new bare ground evaporation) than for 2010; this is particularly clear for the period from May to September 2011 (see Fig. 5). If the decrease in RMSD is associated with the new bare ground evaporation, the increase in correlation (from 0.59 to 0.69 ) is mainly due to the new EKF analysis (also, in situ data are different). As demonstrated in Albergel et al. (2010) and de Rosnay et al. $(2011,2012)$ the use of the EKF permits to increase the quality of the soil moisture product compared to the former OI method. The higher water holding capacity observed for 2011 also helps in this way (more realistic decrease of soil moisture after a precipitation event). Correlations of anomaly time-series are 0.53 and 0.54 for 2010 and 2011, respectively.
Table 3. Biases between BEVAP_OLD (control experiment) and in situ data from the stations of the NRCS-SCAN network in 2010. Fraction of bare ground is used as a filter to compute biases.

\begin{tabular}{ccc}
\hline $\begin{array}{l}\text { Fraction of bare } \\
\text { ground thresh- } \\
\text { old considered }\end{array}$ & N stations & $\begin{array}{l}\text { BEVAP_OLD } \\
\text { [control experiment] } \\
\text { Bias }\left(\mathrm{m}^{3} \mathrm{~m}^{-3}\right)\end{array}$ \\
\hline 0.1 & 57 & -0.079 \\
0.2 & 35 & -0.095 \\
0.3 & 35 & -0.095 \\
0.4 & 33 & -0.094 \\
0.5 & 28 & -0.100 \\
0.6 & 28 & -0.100 \\
0.7 & 28 & -0.100 \\
0.8 & 24 & -0.103 \\
\hline
\end{tabular}

3.2 Impact of the new bare ground evaporation on terrestrial microwave emission and comparison with SMOS

The differences between the TB simulated using surface fields from BEVAP_NEW and the one from BEVAP_OLD are computed for each month of 2010, for both $\mathrm{H}$ (horizontal) and $\mathrm{V}$ (vertical) polarizations (referred to as $\mathrm{TBH}$ and TBV) and an incidence angle of $40^{\circ}$, for 06:00 UTC and 18:00 UTC. It is useful to study the sensitivity of the simulated TB to the bare soil parameterization, as a better representation of soil moisture should lead to more realistic TB, a prerequisite for SMOS data assimilation. In terms of mean difference, BEVAP_NEW soil moisture is drier than BEVAP_OLD, so simulated TB are larger with the BEVAP_NEW surface fields. For TBH (18:00 UTC) the global monthly mean biases between the two data set range from $4.72 \mathrm{~K}$ to $7.01 \mathrm{~K}$, with an annual value of $6.2 \mathrm{~K}$. For TBV (18:00 UTC), global monthly mean biases range from $2.94 \mathrm{~K}$ to $4.14 \mathrm{~K}$, with an annual mean difference of $3.7 \mathrm{~K}$. Statistical scores are summarized in Table 5, and Fig. 6 provides a map of the differences between the simulated TB for one month (August 2010 at 06:00 UTC) and one polarization $(\mathrm{H})$. For this month, mean differences are $6.87 \mathrm{~K}$ and $3.96 \mathrm{~K}$, with STD of $15.58 \mathrm{~K}$ and $9.04 \mathrm{~K}$, for $\mathrm{TBH}$ and TBV, respectively (at 06:00 UTC). Positive differences are found in relatively dry areas. A look at the North American continent shows that large differences are found in the western part of the United States, where there is a high fraction of bare ground (accordingly to Fig. 1). Figure 7 shows, (i) the global monthly mean sensitivity between the two TB and (ii) the spatial correlations between each TB data sets and the fraction of bare ground. As expected, there is a slight annual cycle due to the larger distribution of the continental areas in the northern hemisphere. Spatial correlations between bare ground and TB mean sensitivity are on average 0.66 and 0.65 for TBH (06:00 UTC and 18:00 UTC), and 0.61 and 0.61 for TBV (06:00 UTC and 18:00 UTC). 


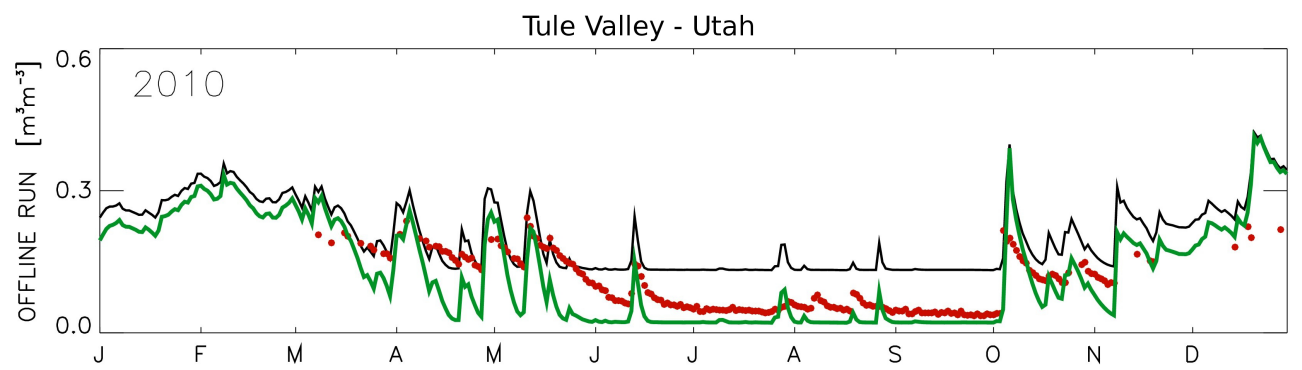

Fig. 4. Illustration of volumetric soil moisture time-series used in this study for one site in Utah (Tule Valley) for 2010. The black line is for BEVAP_OLD (control experiment without the new bare ground evaporation formulation), green line is for BEVAP_NEW (test with new formulation) and red dots are for in situ observations of soil moisture.
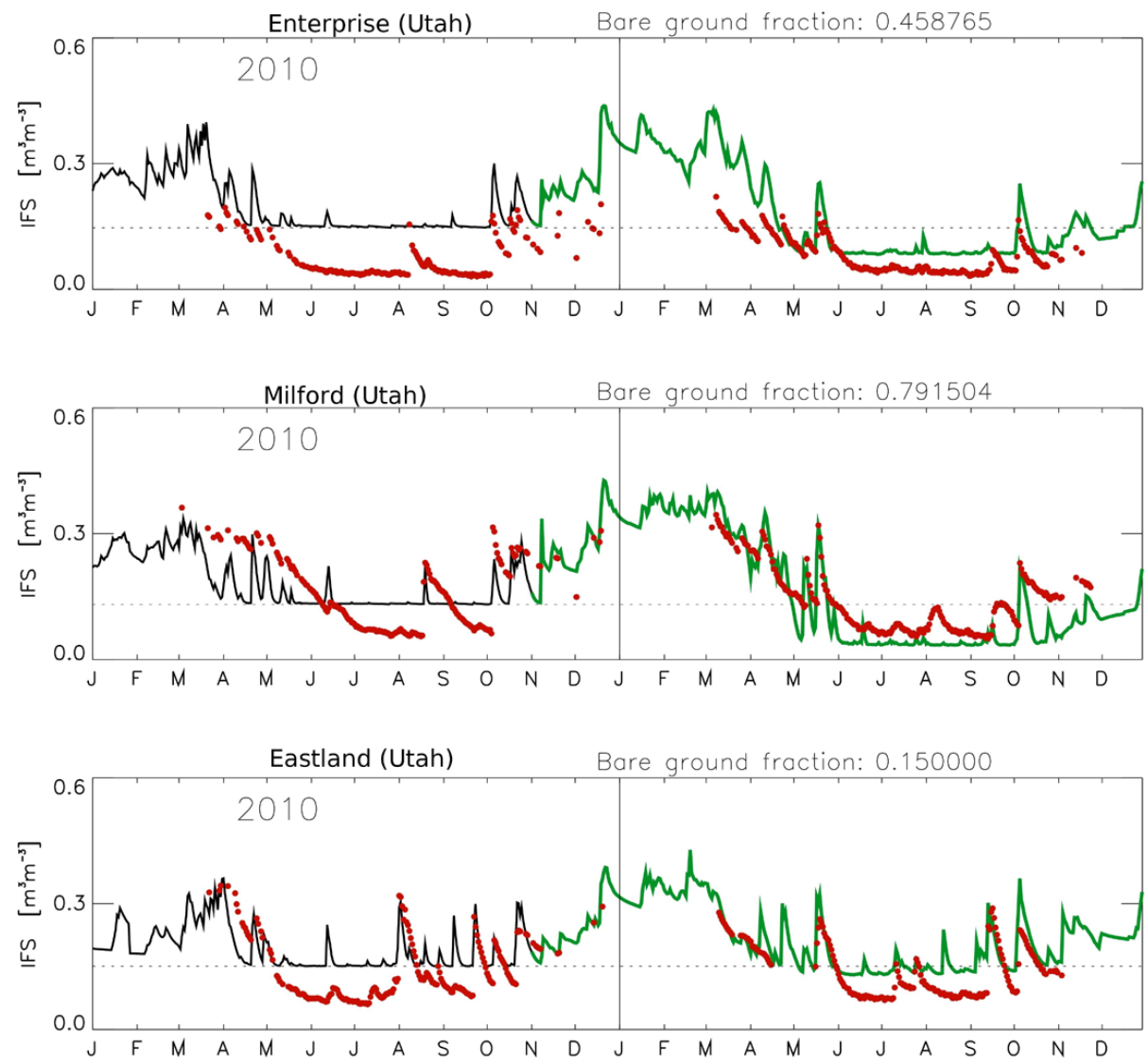

Fig. 5. Time-series of the operational volumetric soil moisture analysis for three sites in Utah for the 2010-2011 period. The black solid line becomes green when the new bare ground evaporation formulation is implemented in November 2010. Red dots are for in situ observations of surface soil moisture. Fraction of bare ground (according to the model) for each site is indicated. The dashed line represents the model minimum soil moisture limit before the implementation of the new bare ground evaporation (permanent wilting point).

Both TB data sets are compared to SMOS TB observations at 06:00 UTC, at an incidence angle of 40 degrees (more data available). Radio frequency interference (RFI) disturbs the natural microwave emission observed by SMOS (Zribi et al., 2011). At an acquisition time of 06:00 UTC, SMOS data are mainly observed over Western Europe and Africa, areas known to be less affected by RFI than others (such as Central Europe for instance). Results are presented in Table 6; it shows that BEVAP_NEW TB are in better agreement with SMOS than BEVAP_OLD TB, with large differences however. The mean difference (for 2010) between SMOS and BEVAP_NEW TBH is $10.2 \mathrm{~K}$ (STD of $21 \mathrm{~K}$ ) and $14.5 \mathrm{~K}$ 
Table 4. Statistical scores for the comparison between ECMWF operational soil moisture analysis for 2010 and 2011 . The new bare ground evaporation formulation was implemented in November 2010. Only stations where the model has a fraction of bare ground greater than or equal to 0.2 were used.

\begin{tabular}{lrrrrr}
\hline Soil Moisture data set & N stations & $R$ & $R$ Anomaly & Bias $\left(\mathrm{m}^{3} \mathrm{~m}^{-3}\right)$ & RMSD $\left(\mathrm{m}^{3} \mathrm{~m}^{-3}\right)$ \\
\hline ECMWF Operational analysis 2010 & 35 & 0.59 & 0.53 & -0.076 & 0.110 \\
ECMWF Operational analysis 2011 & 35 & 0.69 & 0.54 & -0.010 & 0.088 \\
\hline
\end{tabular}

Table 5. Monthly mean statistics of the difference between simulated TB in BEVAP_NEW and BEVAP_OLD. Statistics are given for both horizontal and vertical polarizations, at 06:00 UTC and 18:00 UTC, based on 40 incidence angle simulated TB.

\begin{tabular}{lcccccccc}
\hline \multirow{2}{*}{2010} & \multicolumn{3}{c}{ TBH (BEVAP_NEW) - TBH (BEVAP_OLD) } & \multicolumn{3}{c}{ TBV (BEVAP_NEW) - TBV (BEVAP_OLD) } \\
\cline { 2 - 8 } & \multicolumn{2}{c}{ 06:00 UTC } & \multicolumn{2}{c}{ 18:00 UTC } & \multicolumn{2}{c}{ 06:00 UTC } & \multicolumn{2}{c}{ 18:00 UTC } \\
\cline { 2 - 8 } & Mean Bias (K) & SD (K) & Mean Bias (K) & SD (K) & Mean Bias (K) & SD (K) & Mean Bias (K) & SD (K) \\
\hline January & 5.01 & 13.03 & 4.88 & 12.75 & 3.17 & 8.05 & 3.06 & 7.85 \\
February & 4.93 & 12.79 & 4.72 & 12.49 & 3.06 & 7.82 & 2.94 & 7.62 \\
March & 5.57 & 13.76 & 5.37 & 13.56 & 3.37 & 8.22 & 3.27 & 8.18 \\
April & 6.19 & 15.07 & 6.13 & 15.05 & 3.68 & 9.00 & 3.70 & 9.15 \\
May & 6.59 & 15.46 & 6.66 & 15.69 & 3.90 & 9.19 & 4.01 & 9.50 \\
June & 6.84 & 15.77 & 6.97 & 16.08 & 3.94 & 9.12 & 4.11 & 9.50 \\
July & 6.64 & 15.31 & 6.77 & 15.64 & 3.85 & 8.86 & 4.01 & 9.26 \\
August & 6.87 & 15.58 & 7.01 & 15.95 & 3.96 & 9.04 & 4.14 & 9.47 \\
September & 6.74 & 15.38 & 6.86 & 15.69 & 3.97 & 9.11 & 4.12 & 9.47 \\
October & 6.77 & 15.63 & 6.80 & 15.82 & 4.03 & 9.40 & 4.12 & 9.66 \\
November & 6.63 & 15.49 & 6.50 & 15.40 & 4.04 & 9.52 & 3.99 & 9.55 \\
December & 5.98 & 14.71 & 5.75 & 14.32 & 3.67 & 9.09 & 3.54 & 8.84 \\
\hline
\end{tabular}

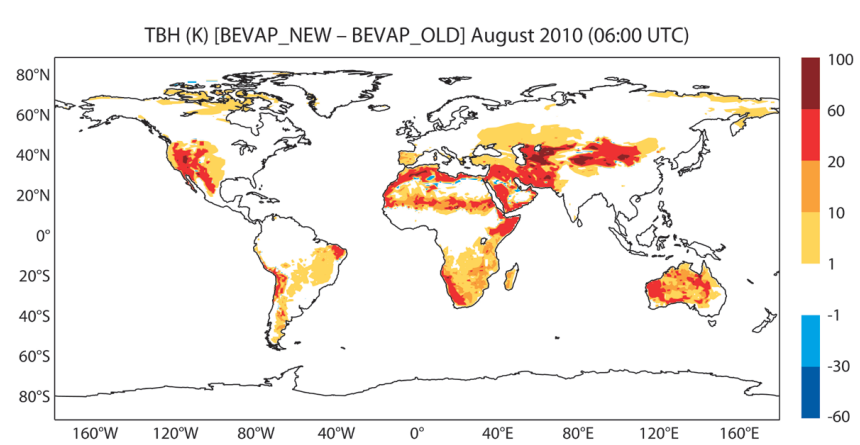

Fig. 6. Map of differences between TB (horizontal polarisation, $40^{\circ}$ incidence angle in $\mathrm{K}$ ) simulated using model fields from BEVAP_NEW and BEVAP_OLD for August 2010 (06:00 UTC).

(STD of $20.8 \mathrm{~K}$ ) when considering BEVAP_OLD TBH. Values are higher for TBV than for TBH.

\section{Discussion}

While previous studies (Albergel et al., 2012a, b) have demonstrated the good ability of ECMWF analyses to represent the soil moisture annual cycle as well as its shortterm variability, they have also shown an overestimation of soil moisture. The modification of the soil moisture inhibition function (Eq. 5) in the new bare ground evaporation formulation allows a much lower level of soil moisture to be reached over bare soil areas as a consequence of direct bare ground evaporation under strong insulation. Results are more realistic when compared to in situ soil moisture values observed over dry areas; they have a smaller RMSD but also a slightly better correlation. The larger water holding capacity induced by the new bare ground evaporation provides a more realistic decrease in soil moisture after a precipitation event. This explains the slightly better correlations obtained with the new formulation for the offline experiments for both the volumetric and the monthly anomaly time-series. Indeed, the latter reflects the time-integrated impact of antecedent meteorological forcing (e.g. precipitation). ECMWF analyses do not assimilate ground-based observation of precipitation. Over land, the information used by the model to generate rain is strongly constrained by in situ measurements of temperature and humidity. The use of precipitation data in the analysis continues to be studied at ECMWF. Lopez (2011) has demonstrated a positive impact on model performance of the direct 4D-Var assimilation of 6-hourly radar and rain-gauge rainfall accumulations. Considering all the stations (122), the differences in RMSDs between the two offline experiments is not very important, 

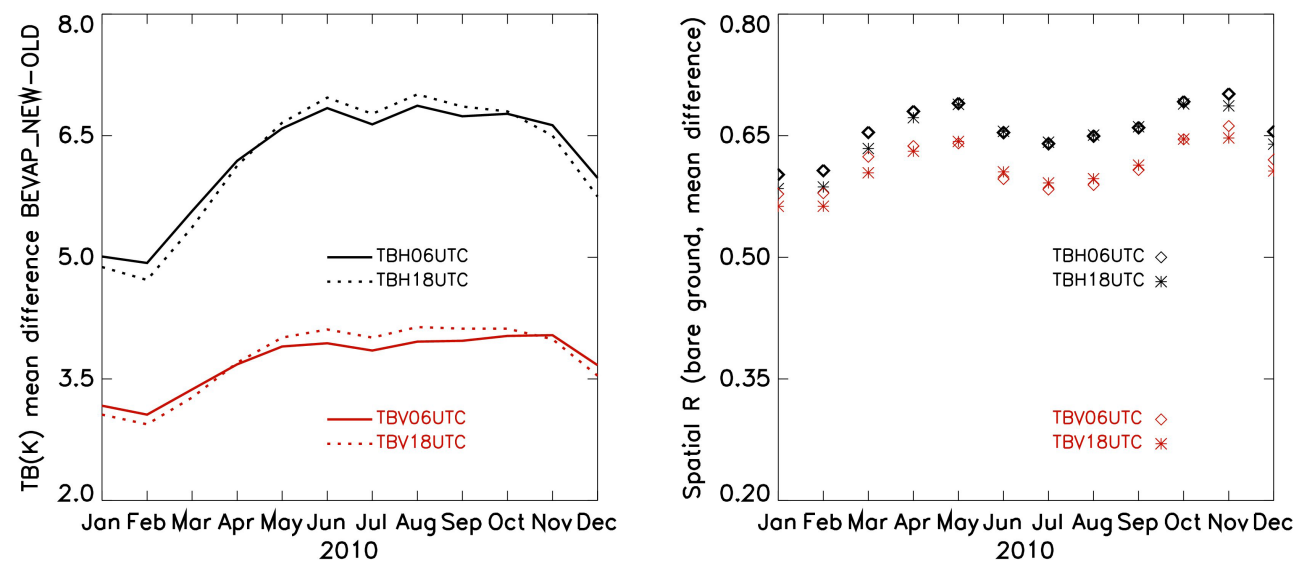

Fig. 7. (left) Brightness temperature global monthly mean sensitivity to the new bare soil parameterization for 2010 (solid and dashed lines), (right) spatial correlation between the fraction of bare ground and the brightness temperature global monthly difference (stars and diamonds). Both horizontal and vertical polarizations (40 incidence angle) are represented for 06:00 UTC and 18:00 UTC.

Table 6. Monthly mean statistics of the difference between SMOS TB observations and simulated TB. Results are given at 06:00 UTC, for both BEVAP_OLD and BEVAP_NEW, at both horizontal and vertical polarizations, based on $40^{\circ}$ incidence angle observed and simulated TB.

\begin{tabular}{lcrrrrrrr}
\hline & \multicolumn{3}{c}{ TB (BEVAP_OLD) 06UTC } & \multicolumn{3}{c}{ TB (BEVAP_NEW) 06UTC } \\
\cline { 2 - 9 } & \multicolumn{2}{c}{ TBH } & \multicolumn{2}{c}{ TBV } & & TBH & & TBV \\
\cline { 2 - 9 } & Mean Bias (K) & SD (K) & Mean Bias (K) & SD (K) & Mean Bias (K) & SD (K) & Mean Bias (K) & SD (K) \\
\hline January & 28.6 & 28.6 & 12.8 & 21.0 & 22.4 & 27.6 & 9.0 & 20.7 \\
February & 28.9 & 28.1 & 12.7 & 20.8 & 22.9 & 27.1 & 9.3 & 20.6 \\
March & 29.5 & 29.7 & 12.7 & 24.3 & 23.2 & 28.8 & 8.9 & 21.6 \\
April & 29.8 & 29.1 & 13.7 & 20.4 & 23.4 & 28.6 & 9.9 & 20.9 \\
May & 31.5 & 28.0 & 14.4 & 20.0 & 24.4 & 27.7 & 10.2 & 20.7 \\
June & 32.6 & 28.9 & 14.8 & 21.1 & 25.5 & 28.7 & 10.6 & 21.7 \\
July & 31.7 & 28.2 & 14.1 & 20.4 & 24.8 & 28.3 & 9.9 & 21.0 \\
August & 33.4 & 28.8 & 15.4 & 20.5 & 58.8 & 29.8 & 11.1 & 21.4 \\
September & 34.2 & 29.1 & 16.5 & 20.7 & 26.6 & 30.3 & 12.1 & 21.8 \\
October & 33.5 & 28.7 & 15.4 & 20.0 & 25.65 & 29.6 & 10.8 & 20.9 \\
November & 32.4 & 28.2 & 14.3 & 19.8 & 24.4 & 28.6 & 9.5 & 20.4 \\
December & 30.0 & 28.2 & 14.5 & 20.4 & 23.8 & 28.1 & 10.8 & 20.4 \\
\hline
\end{tabular}

$0.135 \mathrm{~m}^{3} \mathrm{~m}^{-3}$ and $0.124 \mathrm{~m}^{3} \mathrm{~m}^{-3}$ for BEVAP_OLD and BEVAP_NEW, respectively. However, if a threshold of 0.2 for the fraction bare ground is set, this difference increases to $0.118 \mathrm{~m}^{3} \mathrm{~m}^{-3}$ and $0.087 \mathrm{~m}^{3} \mathrm{~m}^{-3}$. At the spatial resolution of BEVAP_NEW and BEVAP_OLD, ECMWF considers that about $46 \%$ of the land is covered by a fraction of bare ground more than or equal to 0.2. Similar RMSDs are obtained with the operational IFS soil moisture product; in 2010, the RMSD is $0.110 \mathrm{~m}^{3} \mathrm{~m}^{-3}$, and $0.088 \mathrm{~m}^{3} \mathrm{~m}^{-3}$ in 2011 (new bare ground evaporation implemented in November 2010). Results from the recent land surface model developments at ECMWF were evaluated using a land surface benchmarking database gathered for this purpose. Those included field sites from the FLUXNET (http://www.fluxdata.org/) and CEOP (http://www.ceop.net/) observing networks where latent heat, sensible heat and carbon dioxide fluxes measurements are available. For instance, the land surface fluxes results from offline-runs indicated an average improvement of $8 \%$, when adopting the H-TESSEL (BEVAP_NEW) scheme in replacement of the former TESSEL scheme evaluated as RMSD reduction on both the latent and sensible heat fluxes measured over 36 FLUXNET and CEOP flux-towers for 2004 (Balsamo et al., 2012). In the same way, future activities will concern the evaluation of the impact of BEVAP_NEW with respect to BEVAP_OLD in term of surface fluxes. The new bare ground parameterization also shows a consistent signal with the L-band microwave emission. Changes in TB with respect to changes in soil moisture as a result of the new bare ground evaporation is found to be close to $15 \mathrm{~K}$ and $10 \mathrm{~K}$ in $\mathrm{H}$ and $\mathrm{V}$ polarizations, respectively. As the BEVAP_NEW 
soil moisture is drier than BEVAP_OLD, the simulated TB are larger with BEVAP_NEW surface fields. The latter are closer to SMOS observations but with still large global mean differences and standard deviation (about $10 \mathrm{~K}$ and $20 \mathrm{~K}$, respectively). These residual biases are also related to other factors such as the SMOS instrument or input parameters of the radiative transfer model, which are not straightforward to assess. Radio frequency interferences affecting the SMOS measurements could also be responsible of the bias. CMEM configuration used in this study is based on de Rosnay et al. (2009) and Sabater et al. (2011) using AMSR-E C-band data and local L-band data, respectively. Results presented in this study are very preliminary and a full calibration of the CMEM platform, underway at ECMWF for SMOS activities, should lead to more realistic simulated TB, in better agreement with SMOS data.

\section{Conclusions}

This study investigated the new bare ground evaporation formulation implemented in operations at ECMWF in November 2010. Bare ground evaporation over dry lands has been increased by adopting a lower stress threshold than for the vegetation, allowing a higher evaporation. Its impact on soil moisture as well as on the representation of terrestrial microwave emission is assessed. The latter is of particular interest for the planned use of SMOS brightness temperature within the new land-surface analyses, as it will be effective only if realistic and dynamically consistent fields of brightness temperature are simulated as a function of the landsurface conditions. ECMWF has developed offline experiments to assess the impact of model changes. They are produced by a fixed version of the IFS (and used atmospheric forcing from ERA-Interim), while the operational product is based on a continuous effort to improve the analysis and modelling schemes, resulting in frequent updates of the system (a few times a year). So offline experiments make it possible to study the impact of a single modification in the land surface modelling. Even if they are at a coarser spatial resolution than the operational product, they have the benefit of being less time-consuming and are very useful between the completion of future reanalyses of ECMWF.

In situ soil moisture from 122 stations (over 148 available) of the NRCS-SCAN network from all over the United States were used to evaluate the new bare ground evaporation formulation over two periods, 2010 and 2010-2011. It was first assessed using offline experiments to isolate its impact (2010 only) and then using the IFS operational product (20102011). The new scheme results in more realistic soil moisture values, particularly for dry areas; a decrease of about $26 \%$ in RMSD is obtained between the two offline experiments when considering the fraction of bare ground that has a threshold greater than or equal to 0.2 (from $0.118 \mathrm{~m}^{3} \mathrm{~m}^{-3}$ to $0.087 \mathrm{~m}^{3} \mathrm{~m}^{-3}$ ). Slightly higher levels of correlations were also obtained. The same conclusion is reached with the IFS operational analysis where a better agreement with in situ data was found in 2011 than in 2010. More realistic soil moisture also lead to better initial fields for simulating brightness temperature with the CMEM platform, a prerequisite for SMOS data assimilation. This preliminary study demonstrated a better agreement between SMOS data and simulated brightness temperature with surface fields from the new bare ground evaporation. Future improvements of the land-surface physics will focus on evaporation from free water surface such as intercepted water on leaves.

Acknowledgements. Authors thank the EUMETSAT Satellite Application Facility on Support to Operational Hydrology and Water Management "(HSAF)" for their funding support. R. Riddaway from ECMWF is thanked for his valuable comments on the English style. R. Hine from ECMWF is thanked for his help in improving the figures.

Edited by: A. Loew

\section{References}

Albergel, C., Rüdiger, C., Carrer, D., Calvet, J.-C., Fritz, N., Naeimi, V., Bartalis, Z., and Hasenauer, S.: An evaluation of ASCAT surface soil moisture products with in-situ observations in Southwestern France, Hydrol. Earth Syst. Sci., 13, 115-124, doi:10.5194/hess-13-115-2009, 2009.

Albergel, C., Calvet, J.-C., de Rosnay, P., Balsamo, G., Wagner, W., Hasenauer, S., Naeimi, V., Martin, E., Bazile, E., Bouyssel, F., and Mahfouf, J.-F.: Cross-evaluation of modelled and remotely sensed surface soil moisture with in situ data in southwestern France, Hydrol. Earth Syst. Sci., 14, 2177-2191, doi:10.5194/hess-14-2177-2010, 2010.

Albergel, C., de Rosnay, P., Gruhier, C., Muñoz-Sabater, J., Hasenauer, S., Isaksen, L., Kerr, Y., and Wagner, W.: Evaluation of remotely sensed and modelled soil moisture products using global ground-based in situ observations, Remote Sens. Environ., 118, 215-226, doi:10.1016/j.rse.2011.11.017, 2012a.

Albergel, C., de Rosnay, P., Balsamo, G., Isaksen, L., and MuñozSabater, J.: Soil moisture analyses at ECMWF: evaluation using global ground-based in situ observations, J. Hydrometeor., in press, 13, doi:10.1175/JHM-D-11-0107.1, 2012b.

Balsamo, G., Viterbo, P., Beljaars, A. C. M., van den Hurk, B. J. J. M., Hirschi, M., Betts, A. K., and Scipal, K.: A revised hydrology for the ECMWF model: Verification from field site to terrestrial water storage and impact in the ECMWF-IFS, J. Hydrometeor., 10, 623-643, doi:10.1175/2008JHM1068.1, 2009.

Balsamo, G., Boussetta, S., Dutra, E., Beljaars, A. C. M., Viterbo, P., and Van de Hurk, B. J. J. M.: Evolution of land surface processes in the IFS, ECMWF Spring Newsletter, 127, 17-22, 2011.

Balsamo, G., Albergel, C., Balzarolo, M., Beljaars, A., Boussetta, S., Calvet, J. C. , Dutra, E., Kral, T., Papale, D., de Rosnay, P., and Sandu I.: Usefulness of Benchmarking for Global Land Surface Model Development" BAMS Conference notebook, summary from the 26th AMS Conference on Hydrology, 22-26 January, 2012, New Orleans, Louisiana, US, 2012. 
Boussetta, S., Balsamo, G., Beljaars, A. C. M., and Jarlan, J.: Impact of a satellite-derived Leaf Area Index monthly climatology in a global Numerical Weather Prediction model. ECMWF Tech. Memo., ECMWF, Reading, UK, No. 640, 2010.

Bouttier, F.: The development of 12-hourly 4D-Var, ECMWF Tech. Memo 348, 21 pp., 2001.

Choudhury, B. J., Schmugge, T. J., Chang, A., and Newton, R. W. : Effect of surface roughness on the microwave emission for soils, J. Geophys. Res., 84, 5699-5706, 1979.

de Rosnay, P., Drusch, M., Boone, A., Balsamo, G., Decharme, B., Harris, P., Kerr, Y., Pellarin, T., Polcher, J., and Wigneron, J.-P.: The AMMA Land Surface Model Intercomparison Experiment coupled to the Community Microwave Emission Model: ALMIP-MEM, J. Geophys. Res., 114, D05108, doi:10.1029/2008JD010724, 2009.

de Rosnay, P., Drusch, M., Balsamo, G., Isaksen, L., and Albergel, C.: Extended Kalman Filter soil moisture analysis in the IFS. ECMWF Spring Newsletter, 127, 12-16, 2011.

de Rosnay, P., Drusch, M., Vasiljevic, D., Balsamo, G., Albergel, C., and Isaksen, L.: A simplified Extended Kalman Filter for the global operational soil moisture analysis at ECMWF, Q. J. Roy. Meteorol. Soc., in press, doi:10.1002/qj.2023, 2012.

Dee, D. P., Uppala, S. M., Simmons, A. J., Berrisford, P., Poli, P., Obayashi, S., Andrae, U., Balmaseda, M. A., Balsamo, G., Bauer, P., Bechtold, P., Beljaar, A. C. M., van de Berg, L., Bidlot, J., Bormann, N., Delsol, C., Dragani, R., Fuentes, M., Geer, A. J., Haimberger, L., Healy, S. B., Hersbach, H., Holm, E. V., Isaksen, L., Kallberg, P., Kohler, M., Matricardi, M., McNally, A. P., Monge-Sanz, B. M., Morcrette, J.-J., Park, B.-K., Peubey, C., de Rosnay, P., Tavolato, C., Thépaut, J.-N., and Vitart, F.: The ERA-Interim reanalysis: configuration and performance of the data assimilation system, Q. J. Roy. Meteorol. Soc., 137, 553597, doi:10.1002/qj.828, 2011.

Desborough, C. E., Pitman, A. J., and Irannejad, P.: Analysis of the relationship between bare soil evaporation and soil moisture simulated by 13 land surface schemes for a simple non-vegetated site, Global Planet. Change, 13, 47-56, 1996.

Dharssi, I., Bovis, K. J., Macpherson, B., and Jones, C. P.: Operational assimilation of ASCAT surface soil wetness at the Met Office, Hydrol. Earth Syst. Sci., 15, 2729-2746, doi:10.5194/hess15-2729-2011, 2011.

Dirmeyer, P. A., Dolman, A. J., and Sato, N.: The pilot phase of the global soil wetness project, B. Am. Meteorol. Soc., 80, 851-878, 1999.

Dirmeyer, P.A ., Gao, X., and Oki, T.: GSWP-2: The Second Global Soil Wetness Project Science and Implementation Plan, IGPO Publication Series, No. 37, IGPO, 65 pp., 2002.

Dorigo, W. A., Wagner, W., Hohensinn, R., Hahn, S., Paulik, C., Xaver, A., Gruber, A., Drusch, M., Mecklenburg, S., van Oevelen, P., Robock, A., and Jackson, T.: The International Soil Moisture Network: a data hosting facility for global in situ soil moisture measurements, Hydrol. Earth Syst. Sci., 15, 1675-1698, doi:10.5194/hess-15-1675-2011, 2011.

Douville, H., Viterbo, P., Mahfouf, J.-F., and Beljaars, A. C. M.: Evaluation of the optimum interpolation and nudging techniques for soil moisture analysis using FIFE data, Mon. Weather Rev., 128, 1733-1756, 2000.

Douville, H., Chauvin, H., and Broqua, H.: Influence of soil moisture on the Asian and African monsoons. Part I: Mean monsoon and daily precipitation, J. Climate, 14, 2381-2403, 2001.

Drusch, M., Wood, E., and Jackson, T.: Vegetative and atmospheric corrections for soil moisture retrieval from passive microwave remote sensing data: Results from the Southern Great Plains Hydrology Experiment 1997, J. Hydrometeorol., 2, 181-192, 2001.

Drusch, M., Holmes, T., de Rosnay, P., and Balsamo, G.: Comparing ERA-40 based L-band brightness temperatures with Skylab observations: a calibration/validation study using the Community Microwave Emission Model, J. Hydrometeorol., 10, 213226, doi:10.1175/2008JHM964.1, 2009a.

Drusch, M., Scipal, K., de Rosnay, P., Balsamo, G., Anderson, E., Bougeault, P., and Viterbo, P.: Towards a Kalman Filter based soil moisure analysis system for the operational ECMWF integrated forecst system, Geophys. Res. Lett., 36, L10401, doi:10.1029/2009GL037716, 2009b.

Dutra, E., Balsamo, G., Viterbo, P., Miranda, P. M. A., Beljaars, A. C. M., Schär, C., and Elder K.: An improved snow scheme for the ECMWF land surface model: description and offline validation, J. Hydrometeorol., 11, 899-916, 2010.

Entekhabi, D., Asrar, G. R., Betts, A. K., Beven, K. J., Bras, R. L., Duffy, C. J., Dunne, T., Koster, R. D., Lettenmaier, D. P., McLaughlin, D. B., Shuttleworth, W. J., van Genuchten, M. T., Wei, M. Y., and Wood, E. F.: An agenda for land surface hydrology research and a call for the second international hydrological decade, B. Am. Meteorol. Soc., 10, 2043-2058, 1999.

FAO: "Digital soil map of the world (DSMW)", Technical report, Food and Agriculture Organization of the United Nations, re-issued version, 2003.

Hillel, D.: Environmental Soil Physics. Academic Press, 771 pp., 1980.

Holmes, T., Drusch, M., Wigneron, J.-P., and de Jeu, R.: A global simulation of microwave emission: error structures based on output from ECMWFS Operational Integrated Forecast System, IEEE T. Geosci. Remote Sens., 46, 846-856, 2008.

Jarvis, P. J.: The interpretation of the variations in leaf-water potential and stomatal conductance found in canopies in the field, Philos. T. R. Soc. Lond., B723, 385-610, 1976.

Kerr, Y.: Soil moisture from space: where are we?, Hydrogeol. J., 15, 117-120, 2007.

Kerr, Y. H., Waldteufel, P., Wigneron, J.-P., Delwart, S., Cabot, F., Boutin, J., Escorihuela, M.-J., Font, J., Reul, N., Gruhier, C., Juglea, S. E., Drinkwater, M. R., Hahne, A., Martìn-Neira, M., and Mecklenburg, S.: The SMOS Mission: New Tool for Monitoring Key Elements of the GlobalWater Cycle, P. IEEE, 98, 666-687, 2010.

Koster, R. D., Dirmeyer, P. A., Guo, Z. C., Bonan, G., Chan, E., Cox, P., Gordon, C. T., Kanae, S., Kowalczyk, E., Lawrence, D., Liu, P., Lu, C. H., Malyshev, S., McAvaney, B., Mitchell, K., Mocko, D., Oki, T., Oleson, K., Pitman, A., Sud, Y. C., Taylor, C. M., Verseghy, D., Vasic, R., Xue, Y. K., and Yamada, T.: Regions of strong coupling between soil moisture and precipitation, Science, 305, 1138-1140, 2004.

Koster, R. D, Mahanama, S. P. P., Yamada, T. J., Balsamo, G. A., Berg, A., Boisserie, M., Dirmeyer, P. A., Doblas-Reyes, F. J., Drewitt, G., Gordon, C. T., Guo, Z., Jeong, J.-H., Lee, W.-S., Li, Z., Luo, L., Malyshev, S., Merryfield, W. J., Seneviratne, S. I., Stanelle, T., van den Hurk, B. J. J. M., Vitart, F., and Wood, E. F.: The Second Phase of the Global Land-Atmosphere Coupling Experiment: Soil Moisture Contributions to Subseasonal 
Forecast Skill, J. Hydrometeor., 12, 805-822, 2011.

Lopez, P.: Direct 4D-Var Assimilation of NCEP Stage IV Radar and Gauge Precipitation Data at ECMWF, Mon. Weather Rev., 139, 2098-2116, doi:10.1175/2010MWR3565.1, 2011.

Mahfouf, J.-F. and Noilhan, J.: Comparative study of various formulations of evaporation from bare soil using in situ data, J. Appl. Meteorol., 30, 351-362, 1991.

Mahfouf, J.-F.: Analysis of soil moisture from near surface parameters: A feasibility study, J. Appl. Meteorol., 30, 506-526, 1991.

Mahfouf, J.-F. and Rabier, F.: The ECMWF operational implementation of four dimensional variational assimilation. Part II: Experimental results with improved physics, Q. J. Roy. Meteorol. Soc., 126, 1171-1190, 2000.

Mahfouf, J.-F., Viterbo, P., Douville, H., Beljaars, A. C. M., and Saarinen, S.: A revised land-surface analysis scheme in the Integrated Forecasting System, ECMWF newsletter, No. 88 - Summer/Autumn 2000, 8-13, 2000.

Mahfouf, J.-F., Bergaoui, K., Draper, C., Bouyssel, F., Taillefer, F., and Taseva, L.: A comparison of two off-line soil analysis schemes for assimilation of screen level observations, J. Geophys. Res., 114, D08105, doi:10.1029/2008JD011077, 2009.

Rabier, F., Järvinen, H., Klinker, E., Mahfouf, J.-F., and Simmons, A.: The ECMWF operational implementation of four dimensional variational assimilation. Part I: Experimental results with simplified physics, Q. J. Roy. Meteorol. Soc., 126, 1143-1170, 2000.

Rüdiger, C., Calvet, J.-C., Gruhier, C., Holmes, T., De Jeu, R., and Wagner, W.: An intercomparison of ERS-Scat and AMSR-E soil moisture observations with model simulations over France, J. Hydrometeorol., 10, 431-447, doi:10.1175/2008JHM997.1, 2009.

Sabater, J., de Rosnay, P., and Balsamo, G.: Sensitivity of L-band NWP forward modelling to soil roughness, Int. J. Remote Sens., 32, 5607-5620, doi:10.1080/01431161.2010.507260, 2011.

Sabater, J., Fouilloux, A., and de Rosnay, P.: Technical Implementation of SMOS Data in the ECMWF Integrated Forecasting System, IEEE Geosci. Remote Sens. Lett., 9, 252-256, doi:10.1109/LGRS.2011.2164777, 2012.

Schaefer, G. L. and Paetzold, R. F. 2000: SNOTEL (SNOwpack TELemetry) and SCAN (Soil Climate Analysis Network) Presented at the Automated Weather Station (AWS) workshop, 6-10 March, Lincoln, NE.

Seneviratne, S. I., Koster, R. D., Guo, Z. C., Dirmeyer, P. A., Kowalczyk, E., Lawrence, D., Liu, P., Lu, C. H., Mocko, D., Oleson, K. W., and Verseghy, D.: Soil moisture memory in AGCM simulations: analysis of Global Land-Atmosphere Coupling Experiment (GLACE) data, J. Hydrometeorol., 7, 1090-1112, 2006.

Shukla, J. and Mintz, Y.: Influence of land-surface evapotranspiration on the earth's climate, Science, 215, 1498-1501, 1982.

Uppala, S. M., Kallberg, P. W., Simmons, A. J., Andrae, U., Bechtold, V. D., Fiorino, M., Gibson, J. K., Haseler, J., Hernandez, A., Kelly, G. A., Li, X., Onogi, K., Saarinen, S., Sokka, N., Allan, R. P., Andersson, E., Arpe, K., Balmaseda, M. A., Beljaars, A. C. M., Van De Berg, L., Bidlot, J., Bormann, N., Caires, S., Chevallier, F., Dethof, A., Dragosavac, M., Fisher, M., Fuentes, M., Hagemann, S., Holm, E., Hoskins, B. J., Isaksen, L., Janssen, P. A. E. M., Jenne, R., McNally, A. P., Mahfouf, J. F., Morcrette, J. J., Rayner, N. A., Saunders, R. W., Simon, P., Sterl, A., Trenberth, K. E., Untch, A., Vasiljevic, D., Viterbo, P., and Woollen,
J.:The ERA-40 re-analysis, Q. J. Roy. Meteorol. Soc., 131, 29613012, doi:10.1256/qj.04.176, 2005.

van den Hurk, B. J. J. M., Viterbo, P., Beljaars, A., and Betts, A. K.: Offline validation of the ERA-40 surface scheme, ECMWF Tech. Memo., 295, 43 pp., 2000.

van den Hurk, B. and Viterbo, P.: The Torne-Kalix PILPS 2(e) experiment as a test bed for modifications to the ECMWF land surface scheme, Global Plane. Change, 38, 165-173, 2003.

Viterbo, P., Beljaars, A. C. M., Mahfouf, J.-F., and Teixeira, J.: The representation of soil moisture freezing and its impact on the stable boundary layer, Q. J. Roy. Meteorol. Soc., 125, 2401-2426, 1999.

Wagner, W., Blöschl, G., Pampaloni, P., Calvet, J.-C., Bizzarri, B., Wigneron, J.-P., and Kerr, Y.: Operational readiness of microwave remote sensing of soil moisture for hydrologic applications, Nord. Hydrol., 38, 1-20, doi:10.2166/nh.2007.029, 2007.

Wang, L., D’Odorico, P., Evans, J. P., Eldridge, D. J., McCabe, M. F., Caylor, K. K., and King, E. G.: Dryland ecohydrology and climate change: critical issues and technical advances, Hydrol. Earth Syst. Sci., 16, 2585-2603, doi:10.5194/hess-16-25852012, 2012.

Wigneron, J.-P, Waldteufel, P., Chanzy, A., Calvet, J.-C., and Kerr, Y.: Two -D microwave interferometer retrieval capabilities over land surfaces (SMOS mission), Remote Sens. Environ., 73, 270282, 2000.

Wigneron, J.-P., Laguerre, L., and Kerr, Y.: A simple parameterization of the L-band microwave emission from rough agricultural soils, IEEE T. Geosci. Remote Sens., 39, 1697-1707, 2001.

Wigneron, J.-P., Kerr, Y., Waldteufel, P., Saleh, K., Escorihuela, M.J., Richaume, P., Ferrazzoli, P., de Rosnay, P., Gurney, R., Calvet, J.-C., Grant, J.P., Guglielmetti, M., Hornbuckle, B., Mätzler, C., Pellarin, T., and Schwankh, M.: L-band Microwave Emission of the Biosphere (L-MEB) Model: Description and calibration against experimental data sets over crop fields, Remote Sens. Environ., 107,4,639-655, 2007.

World Meteprological Organization: Drought monitoring and early warning: concepts, progress and future challenges, n.1008, ISBN 92-63-11006-9, www.wamis.org/agm/pubs/brochures/ WMO1006e.pdf (last access: 16 April 2012), 2012.

Zribi, M., Pardé, M., Boutin, J., Fanise, P., Hauser, D., Dechambre, M., Kerr, Y., Leduc-Leballeur, M., Skou, M., Søbjærg, S. S., Albergel, C., Calvet, J.-C., Wigneron, J.-P., Lopez-Baeza, E., Saleh, K., Ruis, A., and Tenerelli, J.: Land and ocean calibration and validation of SMOS: the CAROLS airborne campaigns, Sensors, 11, 719-742, doi:10.3390/s110100719, 2011. 